\title{
Conditions for workplace learning: a gender divide?
}

Karin Sjöberg Forssberg

Division of Ergonomics, Royal Insititute of Technology (KTH), Huddinge, Sweden

\author{
Karolina Parding \\ Department of Human Work Sciences, Lulea University of Technology, \\ Luleå, Sweden, and \\ Annika Vänje \\ Division of Ergonomics, Royal Insititute of Technology (KTH), Huddinge, Sweden
}

Received 14 August 2020 Revised 31 October 2020 Accepted 9 November 2020

\begin{abstract}
Purpose - The purpose of this paper is to examine and discuss conditions for workplace learning in gendersegregated workplaces in the public sector, how social constructions of gender contribute to (or constrain) the workplace learning conditions within two workplace contexts.
\end{abstract}

Design/methodology/approach - The research was carried out through an interactive approach with data from 12 semi-structured interviews with workers and first-line managers from technical maintenance and home care in a Swedish municipality, validated at an analysis seminar with 27 participations, from both workplace contexts the Swedish Work Environment Authority and us researchers.

Findings - The results indicate that gender affects conditions for workplace learning and contributes to an enabling learning environment in the male-dominated workplace context and to a constraining learning environment in the female-dominated workplace context. The identified differences are created in both organisational structures and the organisations' cultures.

Research limitations/implications - When analysing conditions for workplace learning from a gender perspective, the approach of comparative, cross-case analyses is useful. An interactive approach with women and men describing and analysing their work experiences together with researchers is a fruitful way of making gender visible.

Practical implications - The theoretical approach in this study illuminates how social constructions of gender operate and affect conditions for workplace learning and contributes to a deeper understanding of underlying causes to unequal conditions in different workplace contexts.

Social implications - The findings imply a gender divide which, from the theoretical strands, can be seen as an expression of asymmetrical power relations and where these gendered learning conditions probably also affect the quality of the services.

Originality/value - The findings contribute to existing gender theoretical literature by demonstrating that gender is essential to take into consideration when understanding working conditions in different workplace contexts. This study contributes to workplace learning literature by exploring the different ways in which social constructions of gender contribute to enabling and constraining learning environments.

Keywords Gender, Workplace learning, Learning environments, Interactive case study

Paper type Research paper

The authors would like to warmely thank the municipalities and the Swedish Work Environment Authority (SWEA) for generously participating in interviews and analysisseminair that led to the results. They would also like to thank the anonymous reviewers for their suggestions.

Funding: The study was funded by AFA Insurance, an organisation owned by Sweden's labour market.

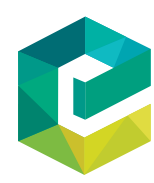

Journal of Workplace Learning (c) Emerald Publishing Limited Emerald Publishing Limited DOI 10.1108/JWL-08-2020-0134 


\section{Introduction}

There are severe work environment issues in the public sector in Sweden affecting possibilities to attract, recruit and retain staff and thus also delivering services of high quality (SKL, 2019). It can be argued that learning in, at, from and for work is essential for the experience of work and also for the possibility to deliver high quality services. Previous research has even shown that good conditions for learning can counteract a work environment which is not optimal. In fact, satisfactory conditions for learning have been argued to be imperative for good health, and they can even function as a buffer to stress (Karasek and Theorell, 1990). This indicates that learning is beneficial for the individual. However, there are benefits for the organisation as well. As an example, reviewing the literature, Lancaster and Di Milia (2015, p. 442) concluded that "organisations that develop their learning capability reportedly benefit from increased job performance, employee selfefficacy, customer satisfaction and profitability". Further, Nylund and Parding (2020) have found that how work is organised, including conditions for learning, correlates with productivity. The situation in the elderly care in Sweden, in relation to the COVID-19 pandemic clearly shows that the work environment, including conditions for workplace learning, is essential for the services delivered. The Swedish Government has, therefore, initiated initiatives with the aim of strengthening learning in elderly care and facilitating the implementation of improvement measures (Regeringskansliet, 2020).

We argue that how conditions for work play out, including conditions for workplace learning, cannot fully be understood by applying workplace learning literature only but needs to be examined taking gender (social constructions) into consideration as well. We argue that how conditions for work, including conditions for workplace learning, play out can be explained by identifying governance logic(s) in place in a work organisation. In other words, workplaces and organisations can be understood as governed by logic-specific values, infusing daily practice and overriding policies. These logics will colour the organisations; they become weaved into the organisation's governance and practices (Svensson, 2011, p. 302). Often, there are several, sometimes conflicting, governance logics in organisations (Evetts, 2006a, 2006b; Freidson, 2001) which in turn affect working conditions and can, for example, lead to stress among employees (Blomgren and Waks, 2015).

However, these logics do not seem to fully capture all the aspects which shape conditions for workplace learning in an organisation. We argue that gender can also be seen as a logic, a logic permeating all aspects of society - not least the working life. An ongoing study indicates that gender may have a greater impact on the work environment than the organisation's steering systems and that the latter can amplify the effects of the prevailing gender order (Johansson and Theodorsson, 2019). It is, therefore, essential to take gender into consideration when understanding what shapes workplace learning conditions (Abrahamsson, 2001; Gustavsson and Fogelberg Eriksson, 2010; Johansson and Abrahamsson, 2018).

This paper is based on a study carried out in Sweden, among employees within the same municipality, with the same employer, though in different workplace contexts, i.e. technical maintenance and homecare services (HCS). As the two workplaces were gender-segregated, we expected them to have well-established formal and informal values regarding gender and thus appropriate for our research questions. Further, we argue, all employees, regardless of function, within the same employer should be expected to have equal working conditions, which refers to the working environment and aspects of employee's terms and conditions of employment (Eurofound, 2011).

The main contribution of this paper is to apply a gender perspective, i.e. how social constructions of gender, affect conditions for workplace learning within organisations by using theories of doing gender and gendered organisations (Acker, 2006, 2012). The aim of 
this paper is to examine and discuss conditions for workplace learning in one male- and one female-dominated workplace, situated in a Swedish Municipality. The research questions are as follows:

$R Q 1$. How are conditions for workplace learning described and experienced by workers and managers?

RQ2. What similarities and differences across the two workplace contexts can be identified?

RQ3. In what way does gender enable or constrain conditions for workplace learning within the two workplace contexts?

In the next section, we present previous research on conditions for workplace learning, pointing out the gap in the research. Thereafter, we discuss how to conceptualise the gendering of organisations. In the method section, we present the context in which this study was conducted and the research approach, along with methodological considerations. Subsequently, we present and discuss our findings, illustrating how the gendering of the studied workplaces help unveil how conditions for workplace learning are shaped. Finally, in the concluding section, we discuss practical and theoretical implications and ways forward for future research.

\section{Previous research on conditions for workplace learning}

By conditions for workplace learning we mean both the formal (e.g. courses) and informal learning (e.g. daily exchange of ideas) (Jansson and Parding, 2011). Further, we assume that workplace learning is about learning integrated into everyday work, sometimes combined with formal learning such as short courses. In the workplace learning literature, it is claimed that how work is organised can either enable or constrain workplace learning (Ellström and Kock, 2008; Ellström et al., 2008). Learning can be "encouraged or obstructed by the design of the organisation" (Ellström and Kock, 2008, p. 17), where aspects such as task orientation, job content perception, work planning and organisation, leadership and organisational and individual readiness to learn are described as comprising important conditions for workplace learning (Ellström et al., 2008). These aspects can be said to constitute the workplace's learning environment (Billett, 2001; Ellström, 1997, 2001; Fuller and Unwin, 2004). When in this paper we examine and discuss conditions for workplace learning, we use a framework based on theories of workplace environments as described above.

Further, Gustavsson and Fogelberg Eriksson (2010) have shown that different and contrasting learning environments are created as a consequence of how gender operates. It is also known that women and men tend not to have equal opportunities for learning and career progression within organisations (Budworth and Mann, 2010; Davidson and Burke, 2004; Wood, 2008). Hearn and Piekkari (2005) note that gender differences are difficult to detect because they are usually explained by women's and men's ways of being rather than by differences in work environment conditions. Gender segregating and stereotypical gender coding of workplaces and work tasks are strong restoring mechanisms and obstacles to strategic organisational changes and to individual and organisational learning (Abrahamsson, 2001). A literature review (Johansson and Abrahamsson, 2018) also confirms that gender-equal organisations constitute a prerequisite for workplace learning. Based on this, we, therefore, argue that there is a need for further research on how gender, as a logic in organisations, affects conditions for workplace learning.

Conditions for workplace learning

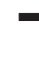




\section{Doing gender and gendered organisations as analytical tools}

Gender in this paper refers to social constructions of gender, gender as something we do, rather than something we are, expressed through mundane practices (Acker, 1999; Gherardi, 1994; Korvajärvi, 1998; Wahl, 2014; West and Zimmerman, 1987). Further, we have a processual view on organisations (Acker, 2006, 2012), where the individual and organisational levels are gendered and integrated into each other (Acker, 1990; Pecis and Priola, 2019). This processual view on both organisations and gender open up for change, once it is illustrated how the organisation is gendered as doing gender often is unintentional and un-reflexive (Amundsdotter, 2009; Martin, 2006).

Using doing gender and gendered organisations as analytical tools implicate that we strive to identify gendered substructures in the two work environment contexts. Gendered substructures in organisations are essential and created by several components such as organising processes and culture, workplace interactions and gendered identities (Acker, 2012). Organising processes can include job design, wage determination, distribution of decision-making and supervisory power, the physical design of the workplace and informal and formal rules for behaviour at work. The latter can consist of policies, work environment acts, formal working hours, etc. (Acker, 2012). These processes are often hidden within systems which can, without gender awareness, appear gender neutral (Martin, 2006). Further, a work culture characterised by the denial and invisibility of doing gender perpetuates the inequities and undermines development attempts (Acker, 2012). Formal and informal interactions through networking or meetings between colleagues and managers also contribute to create gendered substructures in organisations. Finally, gendered identities include individual gendered identities constructed at the workplace but also identities brought into the workplace by individuals (Acker, 2012). A gendered identity can regard the professional role and one's own or others' expectations (Acker, 1990). To conclude, doing gender and organising work are tightly interwoven processes and by analysing conditions for workplace learning using theories about gendered organisations, we can describe how and explain why different workplace contexts experience different conditions, even within the same organisation, in a richer manner than previously done.

\section{Method}

\section{Context, sample and data collection}

This paper is based on a case study which constitutes one part of a larger interactive research project on gender and work environment development in the public sector (Aagaard Nielsen and Svensson, 2006). The findings emanate from two gender-segregated workplace contexts within a Swedish municipality $(100,000$ inhabitants and about 9,000 employees): female-dominated homecare and male-dominated technical maintenance. These two workplace contexts (Table 2) were chosen, as they could be expected to be based on strong gendered norms and as such provide good data that correspond to the aim of this research.

Semi-structured interviews were performed as one part of this case study, as letting women and men describe their work experiences is a fruitful way of making social constructions of gender visible (Martin, 2006). In total, 12 interviews were undertaken with workers (HCS workers: HCS workers and technicians) and managers representing the two operations (Table 1). The respondents were expected to capture both female and male experiences at the workplace. The interviews that were conducted at the workplaces lasted for about $60 \mathrm{~min}$, were audio recorded and then transcribed verbatim. Interviewing on the work premises provided opportunities to make observations, and hand notes were taken in direct connection with the visits. An analysis seminar carried out as an interactive dialogue 


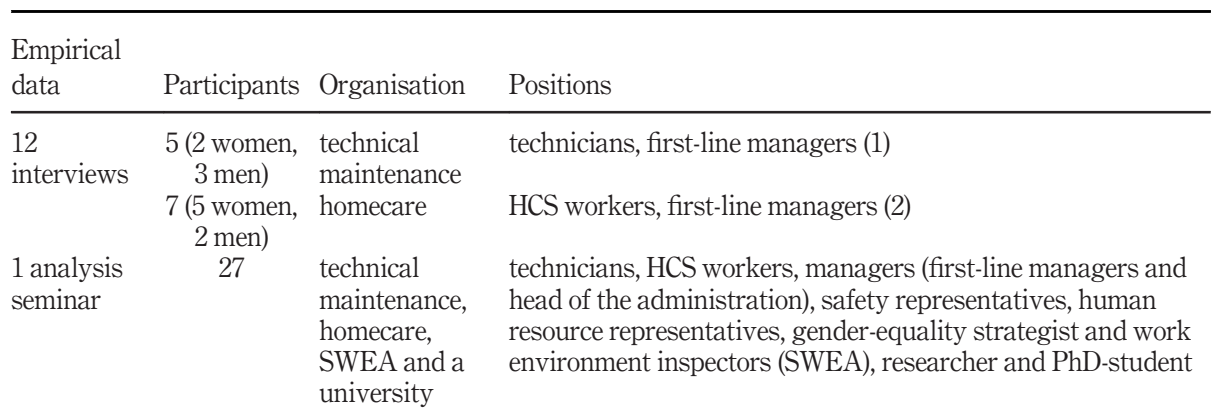

Note: Field notes and observations on data collection occasions, during and directly after each activity are also empirical data
Conditions for workplace learning

Table 1. Empirical data

with workers and managers (informants included) representing the concerned municipality, another municipality, the Swedish Work Environment Authority (SWEA) as well as researchers, served as a tool for validation of the interviews (Table 1).

\section{Data analysis}

The analysis was carried out as a multiple case study (Yin, 1994), where each workplace context (technical maintenance and homecare) were the units of analysis. Jointly, we categorised the statements abductively, meaning that we made the categorisation from a departure in previous research on factors that may impact learning conditions, yet with an openness for new categories. For this approach, we were inspired by an analytic model used by Ellström et al. (2008) in a study of learning environments in public HCSs, especially concerning individual and organisational readiness to learn. Firstly, we analysed the data from each workplace context (within-case analysis). Secondly, we compared the two workplace contexts, i.e. between-case analysis (Yin, 1994). As the workplace contexts were gender-segregated, this theory-guided between-case analysis allowed us to obtain a rich analysis concerning gender aspects. During the between-case analysis, three empirical categories with significant differences between the workplace contexts emerged as central: opportunities for workplace learning, expectations concerning workplace learning and views on one's own competence. These are presented in the next section, followed by a discussion where we interpret processes and practices (organising processes, culture, interactions and gendered identities) contributing to how gender operates and affect conditions for workplace learning. Linkages between the data and existing theories of doing gender and gendered organisations, as presented earlier, as well as identified recurring patterns in our data form the basis of our interpretations of gendered meanings.

\section{Findings}

The results indicate that there are a number of logics operating concurrently in the municipality, shaping conditions for work and, more specifically, conditions for workplace learning. To portray the workplace contexts in which this study took place, which is relevant for understanding the analysis and conclusions drawn, we first present a summary of the key aspects of each workplace context (Table 2). 


\begin{tabular}{|c|c|c|}
\hline Characteristics & Technical maintenance & Homecare \\
\hline \multicolumn{3}{|l|}{ Employee characteristics } \\
\hline Sex & Vast majority of men & $\begin{array}{l}\text { Vast majority of women, but high amount of men in } \\
\text { temporary staff }\end{array}$ \\
\hline Foreign background & None (or few) & More and more, mainly male temporary staff \\
\hline Temporary staff & None & Very large amount \\
\hline \multicolumn{3}{|c|}{ Main conditions in work environment } \\
\hline
\end{tabular}

what is expected

Resources in the execution of the work

Resources for the execution of the work Systematic work environment work

\section{Qualifications}

Table 2.

Workplace context charateristics in technical maintenance and home care emotional recovery

Possibility of flexible working hours the working day Need for coordination with colleagues
Adequate, functional (cars, clothes, tools, premises, etc.). Digital tools and systems are available and used, high level of expertise, access to tablets and laptops Sufficient staffing and enough time for work Focus mainly on the physical work environment-less on the social and organisational High school level, formal education for professional development is paid by the employer

The characteristics of the work

Focus of the work Things

Need for physical or Low. The work is not

Possibility of recovery Possibility to influence heavy, does not involve emotional strain or stress

Sufficient

Sufficient

Sufficient

Small. Opportunity for independent work and work in smaller teams (2 and 2)
Digital tools and systems exist to some extent, but a lot of work is done with paper and pen; insufficient equipment and low ICT-competence

Insufficient staffing and often too little time to complete tasks

Focus mainly on the physical work environment (though most reactive) - less on the social and organisational

Assistant nurse education but the actual level of education is low owing to a high proportion of unskilled temporary workers

People (care receivers, relatives, colleagues) High. The work is physically heavy and involves emotional strain and stress

Insufficient

Insufficient

Small (reactive)

Great need for coordination with colleagues and different occupational categories

In the following, it is illustrated how conditions for workplace learning are described and experienced in the two workplace contexts. The three identified categories constitute the headings.

Opportunities for workplace learning. In both workplace contexts, learning is equated with shorter courses or lectures, i.e. formal learning. The technical maintenance managers offer different courses or lectures and workers may also ask for a course themselves. If there is something many would benefit from, a specific course can be purchased for everyone.

Yes, sometimes I get questions if I want to go to, for example, to that filter school. I thought it was great: but then, if it is something I want to learn about, then I must find out that for myself. And if I find something then, there is no problem [ . . . to acquire further training if you want. It's not that you get a no. (Technical maintenance) 
Within the homecare workplace context, opportunities for formal learning are rare. HCS workers are occasionally offered lectures or courses by the managers. It is unusual that an HCS worker proposes a learning activity and also for the entire team to attend a course together. The technicians are satisfied with their opportunities for workplace learning and they claim that they receive enough training to be able to perform their tasks well and safely. The HCS workers are not that satisfied, as they have limited opportunities for learning in relation to their needs.

[...] there are a lot of drugs and stuff like that now, so a little more updating about medicines, especially wound dressings - there have been lots of new and rescheduling items that I had no knowledge of when I came here. [... I I would like [. . . lectures are great, to sit and listen and get new tips. (Homecare)

The technicians work alone, or in smaller teams of two to three people. They develop specialist competence and have good opportunities for daily exchange of ideas concerning technical problems and various dilemmas they have to deal with. Within the homecare workplace context, there is a constant discussion regarding the care receivers' needs and schedule changes. The constant schedule changes affect the entire team and staffing issues need to be resolved every day, rather than an exchange of ideas that revolve around developing competence in one's job. Indeed, possibilities for workplace learning and daily exchange of ideas concerning professional development seem rare. With a departure from a gender perspective, this can be seen as mirroring how gender is done - there does not seem to be much room for workplace learning in the homecare workplace context, certainly less than in the technical maintenance workplace context.

To summarise, the workers within the two workplace contexts experience different opportunities for workplace learning. These differences in opportunities for initiating and participating in learning activities can be seen as an expression of unequal conditions for workplace learning and as a result of intertwined processes related to gender, hierarchies and power relations.

Expectations concerning workplace learning. In addition to different opportunities for workplace learning, there are also different expectations, both from workers and managers, regarding this dimension. Within technical maintenance, the expectations from managers are described as high, for example, technicians are expected to learn how to use information and communication technology (ICT)-solutions. They also have their own laptops and smartphones, and they report digital data of various kinds.

Yes, exactly, we have everything in the phone because we work a lot through the phone. So, we have like an app there, where we can go in and check. And everything new that happens, "pling": it announces that an e-mail has arrived. (Technical maintenance)

Within the homecare workplace context, expectations from management regarding workplace learning are low, for example, the ICT-competence is described as low, and HCS workers do not have their own laptops. However, everyone has a smartphone though it is not used for work tasks such as sending e-mails or using various systems. Still, most documentation and planning are paper-based and are stored in binders. Notably, basic skills such as sending an e-mail or opening and closing a Word document are absent among many. The work is accordingly adjusted to the low level of ICT-competence.

[...] the first thing we do is to sit down with the caretaker and figure out how they want it to be handled and, yes, what they simply want. And we do that with paper and pen. Then we enter the plan into the computer. And there you can wish that you had a small laptop or something, which
Conditions for workplace learning

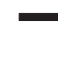


you could take with you and do it directly in the computer, otherwise it will be almost a little double-task, I think. (Homecare)

Differences in work tasks, resources and equipment can be seen as expressions of gendered values regarding the professional areas. Examples include how the meeting premises in homecare lacks technical equipment, while that of technical maintenance is modern and functional. Within homecare, bicycles and electric bicycles are offered as transportation vehicles. However, all HCS workers cannot or do not want to use a bicycle, which is accepted by management. None of the interviewed HCS workers talked about any activities aimed at safer cycling or increasing ICT-skills. In summary, there are gendered differences between the two workplace contexts regarding workplace learning. Even if there are HCS workers who want to learn more about various diseases, etc., the expectations from managers are low, and the work is customised according to the existing knowledge level. The previously described context-related gendered expectations of opportunities for workplace learning can be seen as expressions of unequal conditions, and how gender is socially constructed in the municipality and the two contexts.

Views on one's own competence. The workers in the two workplace contexts have a slightly different focus when describing their own competence, both in terms of what is in focus and how professional development should be undertaken. The technicians focus on the need to improve their own working environment, based on safety aspects and the needs of the clients. Within homecare, the formally approved and desired demands of the care receivers are in focus. It is expressed through statements like "we work with the heart" and "these are people we are dealing with". While the technicians are careful about having the right competence and skills for different types of work, HCS workers, with their constant need for re-prioritisation and problem-solving, focus on the care receivers' demands at the expense of their own safety and work environment. The HCS workers also describe the work as complicated and requiring a number of skills.

Yes, if you work in homecare I usually say that you could almost apply to Dramaten [a theatre] because you can visit up to 6-7 different people in one day and you have to have six different behaviours and manners when you come. [.. . . You have to have a professional way [. . . ] it can be a lot of illness, it can be anxiety [... . we see a lot every day, so you have to be quite openminded as a person and be able to receive but not give too much, then they eat you up. And it can take time to learn and some can't handle it. (Home care)

At the same time, both workers and managers within homecare explain that competence is more about experience and personality than something achieved from organised learning activities.

However, this job also means that you are a bit of a chameleon. I can go to Sven where I can't be "you" I have to be "Sir", then I come to Elsa who meets me every morning with a hug. So, this is something you learn and develop, the older you get, do you get me? (Home care)

In technical maintenance, the approach is different: competence is in this workplace context considered as a result of workplace learning. We assume that these different views on professional competence is an expression of how gender is done and that by extension it affects conditions for workplace learning.

\section{Two different and gendered learning environments}

Although gender and organisation are closely interwoven, the theory-guided between-case analysis highlighted different patterns regarding conditions for workplace learning and 
aspects of gender, which in turn implicate different types of learning environments in the two workplace contexts. As argued below, these contexts may be interpreted as representing an enabling and constraining type of learning environment (Figure 1).

\section{Discussion}

In this section, we discuss employers' and managers' descriptions and experiences of conditions for workplace learning in relation to gender in terms of organising processes, culture, interactions and gendered identities (Acker, 2012). Individual and organisational patterns that enable or constrain workplace learning within the two workplaces are identified, i.e. we have identified two different and gendered learning environments. While it could be expected to be differences in the respondents' descriptions owing to sex or position, we found a rather unison description of the two different learning environments, something that also was validated at the analysis seminar.

We can clearly see that the male-dominated workplace is characterised by working conditions and a learning environment that enables workplace learning. Our findings show that the balance between requirements and recourses, sufficient resources and equipment, no temporary staff and the low degree of unskilled workers provides a good foundation for creating an enabling learning environment. This can also be described in terms of gendered symbols, as these preconditions are an expression of a highly valued workplace in the municipality (Acker, 2006, 2012). In contrast, the female-dominated workplace (homecare) is characterised by poor working conditions and a learning environment that constrains workplace learning. The work environment in homecare reveals imbalances between requirements and resources, lack of equipment and a high amount of unskilled temporary staff. This can be seen as an expression of gendered power relations and values, which creates a foundation for a constraining learning environment (Abrahamsson, 2001; Gustavsson and Fogelberg Eriksson, 2010; Acker, 2012; Johansson and Abrahamsson, 2018). Examples include how the different opportunities to initiate and participate in workplace learning created different possibilities and gender inequalities in the municipality (Abrahamsson, 2001).

Our findings also indicate different cultures regarding expectations concerning workplace learning and professional identity (Acker, 2012). A technician is viewed as being
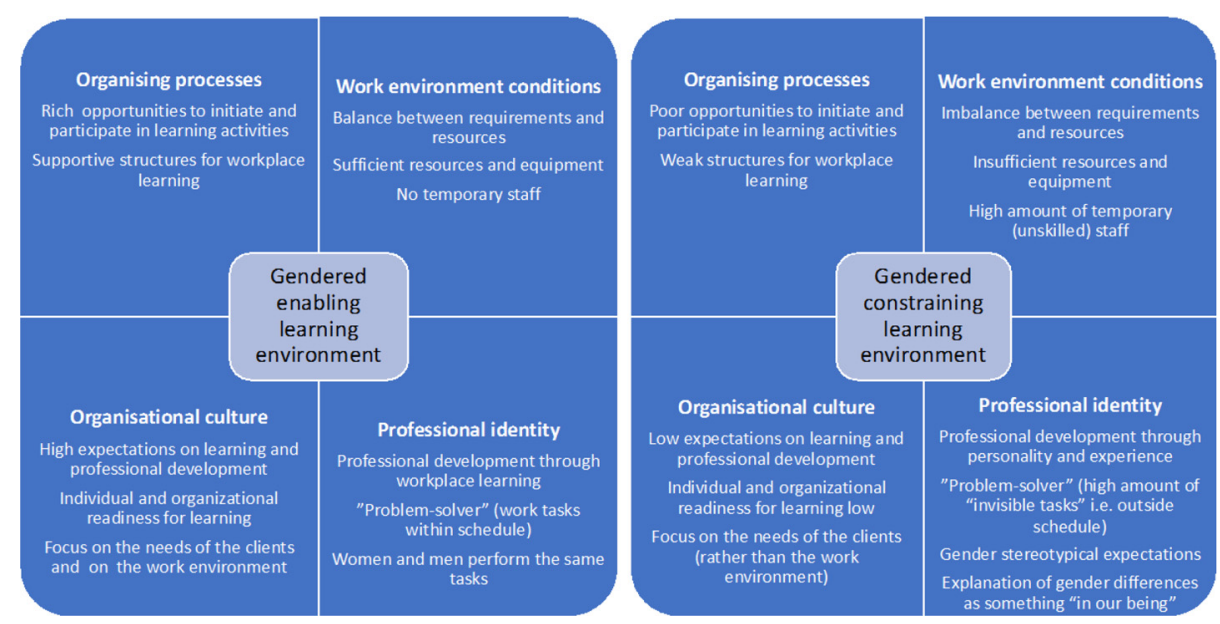

Conditions for workplace learning

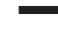


a skilled professional, which requires continuous competence development (workplace learning).

The culture in the technical workplace context is characterised by managers with high expectations for learning. We identified the opposite in homecare, where the organisation instead adapts to the existing knowledge level, a situation that affects the possibilities of learning and developing professional skills. Homecare work is viewed as something depending on a natural talent, something in your being (Purkis et al., 2011), rather than being a skilled professional role. In homecare, we also found that even though everyone performs the same job there are gender stereotypical expectations regarding what women and men can and should do. Gender differences are explained as depending on "our being" rather than on organisational conditions and a social gender order. This view of explaining gender differences as something in women's being rather than by different conditions in the work environment, we argue, constrains workplace learning within the homecare workplace context (Hearn and Piekkari, 2005; Abrahamsson, 2001). Symbols and professional identity are examples of processes and practices of organising that continually create gender inequalities (Acker, 1999). In both workplace contexts the workers identify themselves as "problem-solvers", even if they operate in different conditions of workplace learning. In the technical workplace context, it is possible to manage problems within the scheduled time and no temporary staff is required. In homecare, there are a large amount of "invisible work tasks" performed outside the scheduled time and a lot of temporary staff is required. We claim that this is another expression of gendered substructures and in equal regimes (Acker, 2006). This inequality and lack of resources in terms of time and opportunities for learning constrain possibilities for workplace learning. We also note that homecare is characterised by a high proportion of temporary workers who are men with a foreign background, which makes us assume that gender perspectives do not stand alone but intersect with and are shaped by class and race processes (Acker, 2012; SOU, 2014).

\section{Conclusions}

An overall conclusion is that the gender order in society, based on segregation and hierarchisation (Hirdman, 1990), is strong and reflected into the municipality's work environments. This is in line with previous research describing male dominated technical work as highly valued (Knights, 2019) and female dominated home care service work characterised by low status (Keisu et al., 2016). The constraining learning environment in home care is, we argue, a result of how gendered practices, on both organisational and individual levels, together with other logics operating in the work environment, shape conditions for workplace learning. The gender order, based on unequal power distribution, can be seen as a strong restoring mechanism within work organisations and can provide some explanation as to why work organisations' structures are so resilient and hard to change (Baude, 1992; Abrahamsson, 2001).

The identified gendered differences between the two workplace contexts are created by the following:

(1) conditions in the work environment and organisational processes such as structures for workplace learning; but also by

(2) the organisations' culture with different expectations concerning workplace learning and gendered professional identities.

This implies a gender divide which, from our theoretical strands, can be seen as an expression of asymmetrical power relations and where these gendered learning conditions 
probably also affect the quality of the services (Karasek and Theorell, 1990; Nylund and Parding, 2020).

Regarding practical implications, one conclusion is that when analysing conditions for workplace learning from a gender perspective, a comparative approach is useful, as it effectively highlights whether there are gendered and uneven power relations, distributions of resources and conditions for workplace learning. In this case, we could by applying a gender critical perspective make poor learning conditions in homecare visible and deepen the understanding of underlying causes to these unequal conditions. Further, the interactive approach with women and men describing and analysing their work experiences together with researchers is fruitful in attempts to make social constructions of gender visible. For future research, we suggest studies concerning the interplay between different logics such as political steering and gender and how this enables or constrains conditions for workplace learning in different kinds of operations.

\section{References}

Aagaard Nielsen, K. and Svensson, L. (Eds) (2006), Action Research and Interactive Research, Shaker Verlag, Maastricht.

Abrahamsson, L. (2001), "Gender-based learning dilemmas in organizations", Journal of Workplace Learning, Vol. 13 Nos 7/8, pp. 298-307.

Acker, J. (1990), "Hierarchies, jobs, bodies: a theory of gendered organizations", Gender and Society, Vol. 4 No. 2, pp. 139-158.

Acker, J. (1999), “Gender and organizations”, in Saltzman Chafetz J. (Ed.), Handbook of the Sociology of Gender, Kluwer Academic Plenum Publishers, New York, NY.

Acker, J. (2006), "Inequality regimes: gender, class and race in organizations", Gender and Society, Vol. 20 No. 4, pp. 441-464.

Acker, J. (2012), “Gendered organizations and intersectionality: problems and possibilities”, Equality, Diversity and Inclusion: An International Journal, Vol. 31 No. 3, pp. 214-224.

Amundsdotter, E. (2009), Att Framkalla Och Förändra Ordningen. Aktionsorienterad Genusforskning För Jämställda Organisationer, Universitetstryckeri, Luleå.

Baude, A. (1992), "Kvinnans Plats På Jobbet (the Woman "s Place at Work), SNS, Stockholm.

Billett, S. (2001), "Learning through work: workplace affordances and individual engagement", Journal of Workplace Learning, Vol. 13 No. 5, pp. 209-214.

Blomgren, M. and Waks, C. (2015), "Coping with contradictions: hybrid professions managing institutional complexity", Journal of Professions and Organization, Vol. 2 No. 1, pp. 78-102.

Budworth, M.-H. and Mann, L.S. (2010), "Becoming a leader: the challenge of modesty for women", Journal of Management Development, Vol. 29 No. 2, pp. 177-186.

Davidson, M.J. and Burke, R.J. (2004), "Women in management: facts, figures and analysis - an overview", in Davidson, M.J. and Burke, R.J. (Eds), Women in Management Worldwide: Facts, Figures and Analysis, Ashgate Publishing Limited, London.

Ellström, P.-E. (1997), "The many meanings of occupational competence and qualification”, Journal of European Industrial Training, Vol. 21 Nos 6/7, pp. 266-274.

Ellström, P.-E. (2001), "Integrating learning and work: problems and prospects", Human Resource Development Quarterly, Vol. 12 No. 4, pp. 421-435.

Ellström, P.-E. and Kock, H. (2008), "Competence development in the workplace: concepts, strategies and effects", Asia Pacific Education Review, Vol. 9 No. 1, pp. 5-20.
Conditions for workplace learning 
Ellström, E., Ekholm, B. and Ellström, P.-E. (2008), “Two types of learning environment: enabling and constraining, a study of care work", Journal of Workplace Learning, Vol. 20 No. 2, pp. 84-97.

Eurofound (2011), available at: www.eurofound.europa.eu/observatories/eurwork/industrial-relationsdictionary/working-conditions (accessed 12 October 2020).

Evetts, J. (2006b), "Introduction: trust and professionalism: challenges and occupational changes", Current Sociology, Vol. 54 No. 4, pp. 515-531.

Evetts, J. (2006a), "Organizational and occupational professionalism: the challenge of new public management", Paper presented at XVI World Congress of Sociology, 23-29 July, Durban.

Freidson, E. (2001), Professionalism: The Third Logic, Polity Press, Cambridge.

Fuller, A. and Unwin, L. (2004), "Expansive learning environments: integrating organizational and personal development", in Rainbird, H., Fuller, A. Munro, A. (Eds), Workplace Learning in Context, Routledge Taylor and Francis group, London/New York, NY.

Gherardi, S. (1994), "The gender We think, the gender we do in our everyday organizational lives", Human Relations, Vol. 47 No. 6, pp. 591-610.

Gustavsson, M. and Fogelberg Eriksson, A. (2010), "Gendered learning environments in managerial work", Studies in the Education of Adults, Vol. 42 No. 2, pp. 141-155.

Hearn, J. and Piekkari, R. (2005), "Gendered leaderships and leadership on gender policy: national context, corporate structures and chief human resources managers in transnational corporations", Leadership, Vol. 1 No. 4, pp. 429-454.

Hirdman, Y. (1990), “Genussystemet”, In Demokrati Och Makt i Sverige, (SOU 1990:44), Fritzes, Stockholm.

Jansson, A. and Parding, K. (2011), "Changed governance of public sector organizations = challenged conditions for intra-professional relations?", International Journal of Public Sector Management, Vol. 24 No. 3, pp. 177-186.

Johansson, K. and Abrahamsson, L. (2018), "Gender-equal organizations as prerequisite for workplace learning”, The Learning Organization, Vol. 25 No. 1, pp. 10-18.

Johansson, V. and Theodorsson, A. (2019), "Arbetsmiljöarbete i politikerstyrda och könssegregerade organisationer", In Arbetsmiljöarbete och ohälsa i ett genusperspektiv. Uppdragsforskning med relevans för tillsynsverksamheten, The Swedish Work Environment Authority, Rapport 2019:7.

Karasek, R. and Theorell, T. (1990), "Healthy work: stress", Productivity, and the Reconstruction of Working Life, Basic Books, New York, NY.

Keisu, B.-I., Öhman, A. and Enberg, B. (2016), "What is a good workplace? Tracing the logics of NPM among managers and professionals in Swedish elderly care", Nordic Journal of Working Life Studies, Vol. 6 No. 1, pp. 27-46, doi: 10.19154/njwls.v6i1.4884.

Knights, D. (2019), "Gender still at work: Interrogating identity in discourses and practices of masculinity”, Gender, Work and Organization, Vol. 26 No. 1, pp. 18-30, doi: 10.1111/ gwao.12338.

Korvajärvi, P. (1998), Gendering Dynamics in White-Collar Work Organizations, University, Tampere.

Lancaster, S. and Di Milia, L. (2015), "Developing a supportive learning environment in a newly formed organisation", Journal of Workplace Learning, Vol. 27 No. 6, pp. 442-456.

Martin, P.Y. (2006), "Practicing Gender at Work: Further Thoughts on Reflexity", Gender Work and Organization, Vol. 13 No. 3, pp. 254-276.

Nylund, A. and Parding, K. (2020), “Goda lärandevillkor i arbetet ger hög arbetsproduktivitet", Tidskriften arbetsmarknad och arbetsliv.

Pecis, L. and Priola, V. (2019), "The 'new industrial man' as unhero: doing postfeminist masculinities in an Italian pharmacological research Centre", Gender, Work and Organization, Vol. 26 No. 10, pp. 1-20, doi: 10.1111/gwao.12359. 
Purkis, M., Ceci, C. and Bjornsdóttir, K. (2011), "Patching up the holes: analysing paid care work in homes", in Benoit, C. and Hallgrimsdottir, H. (Eds), Valuing Care Work Comparative Perspectives, University of Toronto Press, Toronto, pp. 89-106, doi: 10.3138/9781442689992.

Regeringskansliet (2020), available at: www.regeringen.se/pressmeddelanden/2020/04/uppdrag-attanalysera-risker-inom-vard-och-omsorg-till-foljd-av-covid19/ (accessed 13 August 2020).

SKL (2019), “Arbetsmiljön i kommuner och regioner", available at: https://webbutik.skr.se (accessed 13 August 2020).

SOU (2014), Inte Bara Jämställdhet. Intersektionella Perspektiv på Hinder Och Möjligheter i Arbetslivet, (SOU 2014:34), Fritzes.Stockholm.

Svensson, L.G. (2011), "Profession, organisation, kollegialitet och ansvar", Socialvetenskaplig Tidskrift $n r$ 4, s, pp. 301-319.

Wahl, A. (2014), "Male managers challenging and reinforcing the male norm in management", NoraNordic Journal of Feminist and Gender Research, Vol. 22 No. 2, pp. 131-146.

West, C. and Zimmerman, D. (1987), "Doing gender”, Gender and Society, Vol. 1 No. 2, pp. 125-151.

Wood, G.J. (2008), "Gender stereotypical attitudes: past, present and future influences on women"s career advancement”, Equal Opportunities International, Vol. 27 No. 7, pp. 613-628.

Yin, R.K. (1994), Case Study Research: Design and Methods, Sage Publication, London.

\section{Corresponding author}

Karin Sjöberg Forssberg can be contacted at: karinsf@kth.se

For instructions on how to order reprints of this article, please visit our website:

Conditions for workplace learning 